\title{
Comportamento sexual de Loxosceles laeta (Nicolet) (Araneae, Sicariidae): influência da idade da fêmea
}

\author{
Marta L. Fischer \\ Núcleo de Estudos do Comportamento Animal, Departamento de Biologia, CCBS, Pontifícia Universidade Católica do Paraná. \\ Avenida Silva Jardim 1664/1101, 80250-200 Curitiba, Paraná, Brasil. E-mail: marta.fischer@pucpr.br
}

\begin{abstract}
Sexual behavior of Loxosceles laeta (Nicolet) (Araneae, Sicariidae). Loxosceles laeta (Nicolet, 1849) is a cosmopolitan species with great resistance and longevity which favors its passive distribution for different countries. In the municipal district of Curitiba, south Brazil, this species represents $10 \%$ of the occurrences. In view of the medical importance and the need for understanding distribution and colonization patterns of antropic environments by species of the genus Loxosceles, the objective of the present study was to characterize the sexual behavior of $L$. laeta. A number of 60 couples represented by old and young virgin females with virgin males were analyzed. The sexual behavior of $L$. laeta was characterized by the intense use of the web and for the exhibition of motor patterns related to higher levels of aggressivity when compared with other species of the genus. In old females the predominant motor patterns were linked to a larger receptivity. However, the interactions were longer which seems that this pattern may be related to the larger amount of webs found in the container. The sexual behavior exhibited by $L$. laeta characterizes his sedentary habit and aggressiveness.

KEY WORDS. Curitiba; Loxosceles intermedia; poisonous.
\end{abstract}

RESUMO. Loxosceles laeta (Nicolet, 1849) é uma espécie cosmopolita que possui grande resistência e longevidade o que favoreceu a sua distribuição passiva por diferentes países, porém no município de Curitiba representa $10 \%$ das ocorrências. Tendo em vista a importância médica e a necessidade de compreensão dos padrões envolvidos na distribuição e colonização dos ambientes antrópicos pelas espécies do gênero Loxosceles, o presente estudo teve como objetivo caracterizar o comportamento sexual de L. laeta. Analisou-se 60 cópulas com fêmeas virgens velhas e novas diante de machos virgens. $O$ comportamento sexual de $L$. laeta foi caracterizado pela intensa utilização da teia e pela exibição de padrões motores relacionados com a sua maior agressividade quando comparada com outras espécies do gênero. Os padrões motores predominantes em fêmeas velhas estiveram ligados com uma maior receptividade, porém as interações foram mais longas, aparentemente este padrão esteve relacionado com uma maior quantidade de teias no recipiente. $\mathrm{O}$ comportamento sexual exibido por $L$. Iaeta caracterizou o sedentarismo e agressividade da espécie.

PALAVRAS-CHAVE. Curitiba; Loxosceles intermédia; peçonhentos.

No continente americano o gênero Loxosceles é dividido em cinco grupos de radiação evolutiva: reclusa, laeta, gaucho, spadicea e amazônica, sendo os quatros últimos representados no Brasil. Os grupos se distinguem principalmente por características morfológicas (e.g. coloração, proporções corporais e genitália) (GERTSCH 1967), embora seja possível de haver também diferenças ecológicas e comportamentais.

Loxosceles laeta (Nicolet, 1849) é a principal integrante do grupo laeta, sendo endêmica do sudoeste da América do Sul (GERTSCH 1967), porém foi introduzida em diferentes países onde ocorre principalmente em focos de infestação (Levi \& SPIELMAN 1964, GerTsch 1967). Entre as espécies ocorrentes na América do Sul, L. laeta é uma das que possui maior tamanho (GERTSCH 1967), é altamente resistente a longos períodos sem água ou alimento (Lowre 1980, 1987) e possui um alto potencial reprodutivo refletido no fato que cada fêmea pode produzir até quinze ootecas durante sua vida (ANDRADE et al. 2000) e cada uma destas pode conter até 138 ovos (Galiano 1973). Sezerino et al. (1998) consideram, ainda, a possibilidade de que os casos mais graves de loxoscelismo (cutâneo visceral) no sul do Brasil sejam decorrentes da picada por L. laeta. Considerando a grande longevidade de L. laeta (Galiano \& Hall 1973, Lowrie 1980) somado com seu hábito sedentário e agressividade (Fischer \& VASCONCELlos-Neto 2005) é possível que haja diferentes padrões comportamentais em fêmeas de diferentes idades e que esses façam parte da estratégia reprodutiva que favoreça o aumento da fecundidade e, automaticamente, a infestação de ambientes antrópicos. 
No Brasil, L. laeta ocupa áreas urbanas predominantemente na região sul sendo simpátrica com Loxosceles intermedia Mello-Leitão, 1931 (Rio Grande do Sul: Buckup 1980; Santa Catarina: SEZerino et al. 1998; e Paraná: Fischer 1994, Fischer \& Vasconcellos-Neto 2005, Marques-da-Silva \& Fischer 2005). Em Curitiba representa $10 \%$ dos registros de ocorrência e colonizou principalmente o intradomicílio de antigas casas de madeiras (Fischer 1994, Fischer \& Vasconcellos-Neto 2005). Fischer \& Vasconecellos-Neto $(2003,2005)$ e Marques-Da-Silva \& Fischer (2005) evidenciaram em seus estudos que a ampla distribuição de L. intermedia está relacionada com seu hábito mais generalista, mais errante e menos agressiva do que L. laeta.

Tendo em vista a importância médica de L. laeta o presente estudo teve como objetivo quantificar os padrões motores exibidos por L. laeta durante seu comportamento sexual.

\section{MATERIAL E MÉTODOS}

O estudo foi conduzido na seção de Artrópodos Peçonhentos do Centro de Produção e Pesquisa de Imunobiológicos (CPPI-SESAPR) de 2003 a 2005, com aranhas presentes em lotes de criação. A criação foi mantida em temperatura de $25 \pm 3^{\circ} \mathrm{C}$ e umidade relativa do ar de $70 \pm 7 \%$, sendo a alimentação semanal composta por uma ninfa de Pycnoscelus surinamensis (Linnaeus, 1767) (Insecta, Blattariae, Blaberidae) ou uma larva de Tenebrio molitor Linnaeus, 1785 (Insecta, Coleoptera, Tenebrionidae).

Os pareamentos foram realizados entre machos virgens e fêmeas virgens velhas $(n=30)$ e novas $(n=30)$. Considerouse como fêmea velha, as aranhas que realizaram a ecdise de maturação em um intervalo maior do que um ano e fêmea nova, em um intervalo máximo de três meses. O recipiente $(240 \mathrm{~mL})$ que a fêmea estava ocupando desde o seu nascimento foi mantido na vertical e aberto, de forma que qualquer uma das aranhas pudesse sair facilmente em qualquer momento da interação. O macho foi introduzido nas teias da fêmea e, então, cronometrado todos os padrões motores exibidos pelo casal. Foram realizados tantos pareamentos quanto necessários para obter 30 cópulas, porém mesmo quando não ocorria cópula, os padrões motores eram registrados. Após a introdução do macho no recipiente da fêmea esperou-se $10 \mathrm{~min}$, caso não apresentasse nenhum movimento era retirado e a interação considerada negativa. Porém, se o macho exibisse padrões motores relativos à fase de pré-cortejo, a interação era avaliada por mais $30 \mathrm{~min}$, após esse intervalo se não houvesse cópula, o macho era retirado e a interação finalizada. Em testes com a ocorrência de cópulas, a interação foi considerada finalizada com a saída do macho do recipiente.

As freqüências dos padrões motores de machos e fêmeas em testes com e sem cópula e com fêmeas velhas e novas foram comparadas através do teste do qui-quadrado. A duração do pré-cortejo, cortejo, pré-cópula, cópula, pós-cópula e da exibição de padrões motores de tremulação de pernas anteriores da fêmea, golpeio e o número médio de inserções dos êm- bolos foi comparado entre fêmea velha e nova através de testes estatísticos Kruskal-Wallis (H) e Mann-Whitney (U), pelo fato dos dados não apresentarem distribuição normal.

O presente estudo foi realizado de acordo com a legislação brasileira, sendo autorizada a captura, transporte, manutenção das aranhas em cativeiro pelo órgão competente (IBAMA-PR) e aprovado pelo comitê de ética em pesquisa com animais (CEUA-PUCPR). A coleção de referência foi tombada no Museu de Zoologia da Pontifícia Universidade Católica do Paraná ( $\left.n^{\circ} 11694\right)$ e na coleção científica Dra. Vera Regina Von Eickstedt do Centro de Produção e Pesquisa de Imunobiológicos (CPPI-SESAPR) ( $\mathrm{n}^{\circ}$ 1724).

\section{RESULTADOS}

Para fêmeas velhas de L. laeta foram realizados 39 testes para se obter 30 cópulas $(50,8 \%)$, enquanto para fêmeas novas foram realizados 108 testes $(25,4 \%)\left(\chi_{(1)}^{2}=32,4 ; \mathrm{p}<0,01\right)$. Em ambas situações, o comportamento sexual ocorreu em cinco etapas: pré-cortejo, cortejo, pré-cópula, cópula e pós-cópula.

\section{Pré-cortejo}

O reconhecimento do casal de L. laeta foi caracterizado por 11 padrões motores que culminaram no toque (Figs 1-3). O tempo médio despendido até o primeiro toque foi $5 \pm 22,9$ segundos ( $\mathrm{n}=277$; i.v = 5-183), e significativamente menor em interações com fêmeas novas $\left(\mathrm{F}_{(203)}=7,3\right.$; $\left.\mathrm{p}<0,01\right)$, não diferindo entre interações que resultaram ou não em cópula (Tab. I). As fêmeas velhas, além de exibirem maior número de padrões motores $(\mathrm{U}=4,6 ; \mathrm{p}<0,01)$, aproximaram-se mais do que as novas $\left(\chi_{(5)}^{2}=26,5 ; \mathrm{p}<0,01\right)$ (Figs 2 e 3 ).

\section{Cortejo}

Após o toque, o macho pode golpear as pernas na teia da fêmea e tocá-la. Então, o casal se posiciona de frente, o macho estira as pernas anteriores na direção da fêmea tocando levemente as extremidades no seu cefalotórax; em seguida dobraas, voltando para posição original e na seqüência exibe um novo golpeio (Figs 1-3). Nesta fase, o sinal mais aparente de receptividade da fêmea foi a tremulação das pernas anteriores na direção do macho. Fêmeas não receptivas elevaram o cefalotórax ao toque do macho, podendo atacá-lo (Figs 1-3).

A freqüência dos padrões motores exibidos diferiu entre fêmea velha e nova $\left(\chi_{(1)}^{2}=113 ; p<0,01\right)$, com a elevação do corpo sendo mais freqüente na nova e a tremulação das pernas, nas velhas (Figs 2 e 3). O tempo médio despendido no cortejo foi significativamente mais longo com fêmea velha $(U=1039 ; p<0,01)$ (Tab. I). Enquanto com fêmeas velhas foi registrado até 15 cópulas em uma mesma interação, com fêmeas novas foram registrados no máximo quatro.

Os dois padrões motores que ocorreram em maior freqüência no cortejo foram o golpeio e a tremulação. O número médio de golpeio por interação foi de $3 \pm 5$ ( $n=277$; i.v. = 0 $21)$, sendo mais freqüente em interações com fêmea velha ( $U=$ 871; p < 0,01) (Tab. I). O número médio de vezes que o padrão 

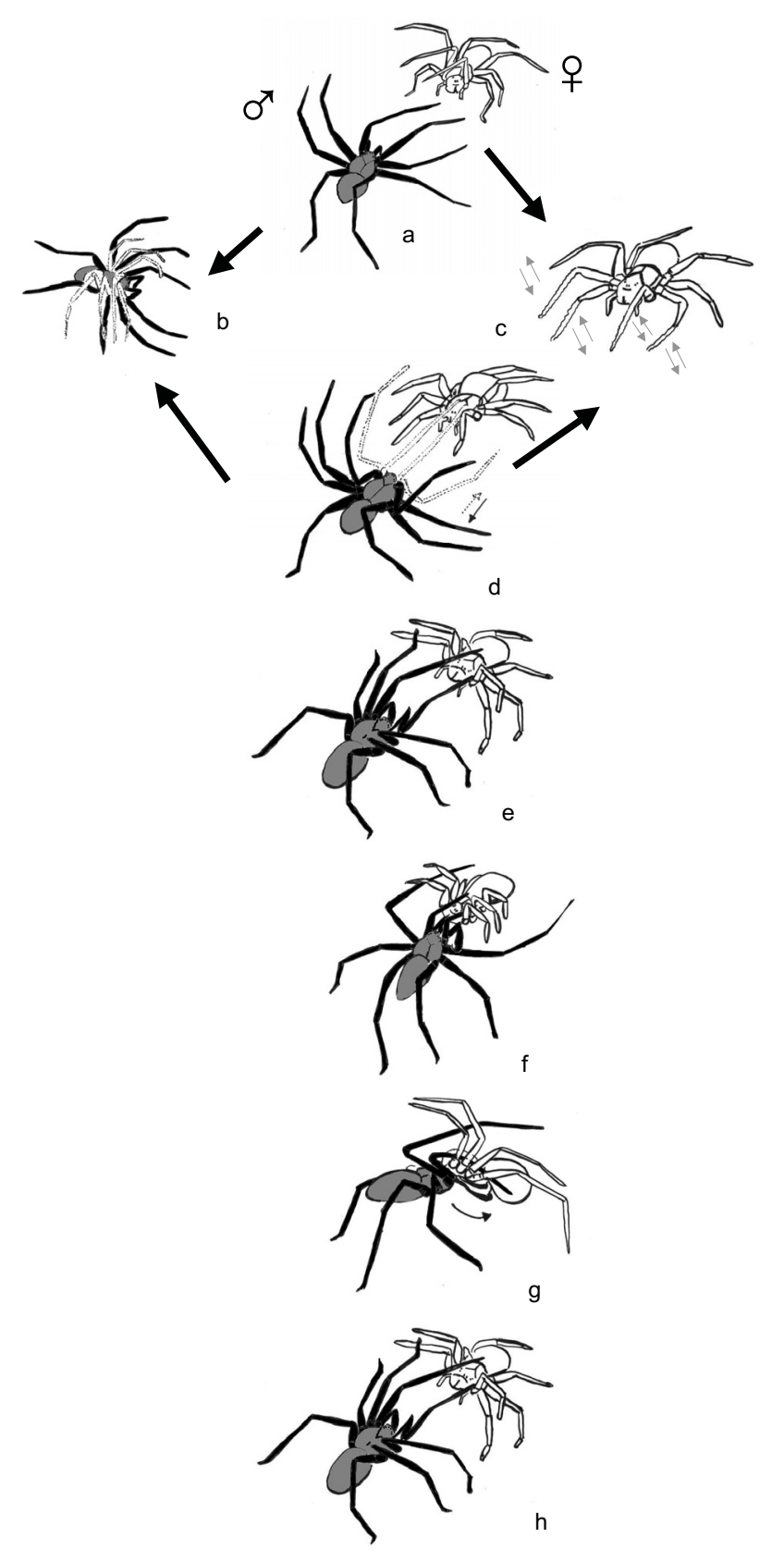

Figura 1. Atos comportamentais exibidos no comportamento sexual de machos (figuras escuras) e fêmeas (figuras claras): Reconhecimento $(a ; b ; c)$; toque das extremidades das pernas anteriores do macho no cefalotórax da fêmea (d; e); pernas anteriores do macho estirado no cefalotórax da fêmea (f); inserção dos êmbolos (g) e padrões motores exibidos após a finalização da cópula (h).

motor de tremulação das pernas da fêmea ocorreu por interação foi de $2 \pm 4,9$ ( $\mathrm{n}=277$; i.v. = 0-38), sendo mais freqüente e mais demorado em fêmeas velhas $(U=861,5 ; p<0,01)$ (Tab. I). Já a duração média da tremulação por cada vez que foi exibida não diferiu entre as fêmeas (Tab. I).

\section{Pré-cópula}

Após o cortejo, o macho estirou o primeiro par de pernas anteriormente e manteve-o no cefalotórax da fêmea, pressionando-o para baixo ou retirando-o, voltando a golpear, reiniciando todo o processo. Caso mantivesse as pernas, o macho deslocou-as para as laterais do cefalotórax da fêmea, encaixando-as entre as coxas, tocando também a região distal da lateral do abdome (Figs 2 e 3). A fêmea em qualquer uma destas etapas pode elevar o corpo ou atacar o macho. O macho retirou mais vezes as pernas ao pressionar o cefalotórax em interações com fêmea velha $\left(\chi_{(1)}^{2}=31,3 ; p<0,01\right)$, enquanto as fêmeas velhas tremularam mais as pernas e as novas elevaram mais o corpo $\left(\chi_{(2)}^{2}=190 ; \mathrm{p}<0,01\right)$ (Fig. 2 e 3 ).

\section{Cópula}

Após o encaixe das pernas do macho na lateral do cefalotórax da fêmea, o macho dobrou as suas pernas na articulação patela/tíbia aproximando a fêmea, então movimentou seus pedipalpos, tocando a patela nas peças bucais da fêmea, estimulando a elevar a região anterior do cefalotórax. Em seguida, o macho abaixou o cefalotórax, se deslocou para baixo da fêmea, estirando os pedipalpos com os êmbolos voltados para cima e os inserindo simultaneamente nas aberturas genitais da fêmea. Em interações com fêmea nova foi registrado o ataque da fêmea no momento em que o macho a aproximou (Figs 1-3).

Os êmbolos permaneceram inseridos por poucos segundos, porém foram inseridos várias vezes seguidas (Tab. I), para tal o macho voltou a tocar a patela dos pedipalpos nas peças bucais da fêmea e inseriu novamente. O número médio de inserções por interação foi de $4 \pm 4,1(\mathrm{~N}=60$; i.v. = 1-25) e o tempo médio de cópula $109 \pm 127$ segundos ( $n=60$; i.v. $=2-806)$, não diferindo entre fêmeas novas e velhas. $\mathrm{O}$ macho pode retirar as pernas do cefalotórax da fêmea, ou estirar as pernas afastandose da fêmea, porém sem a retirada das mesmas. Pode permanecer assim por períodos variáveis, em que movimentava os pedipalpos e procedia a limpeza dos mesmos, passando-os por entre as quelíceras. $\mathrm{O}$ macho pode voltar a puxar a fêmea e realizar os padrões motores descritos acima por inúmeras vezes. $\mathrm{O}$ número médio de cópulas por interação foi de $2 \pm 2,8$ ( $\mathrm{n}=60$; i.v. = 1-16). Na última inserção do êmbolo, precedida da retirada do macho, pode ocorrer o ataque da fêmea (Figs 2 e 3). Porém, mesmo sem o ataque a saída do macho foi abrupta e rápida. $\mathrm{O}$ afastamento do macho sem retirada das pernas do cefalotórax da fêmea foi mais freqüente em fêmea nova e o afastamento direto com a velha $\left(\chi_{(1)}^{2}=99 ; \mathrm{p}<0,01\right)$ (Figs 2 e 3 ).

\section{Pós-cópula}

Após a cópula o macho pode se retirar ou voltar a exibir os padrões motores de golpeio e colocação das pernas anteriores estiradas no cefalotórax da fêmea e exibir os padrões motores acima descritos. A fêmea, após a retirada do macho, pode se aproximar, tremular as pernas anteriores e tocá-lo. A retomada 


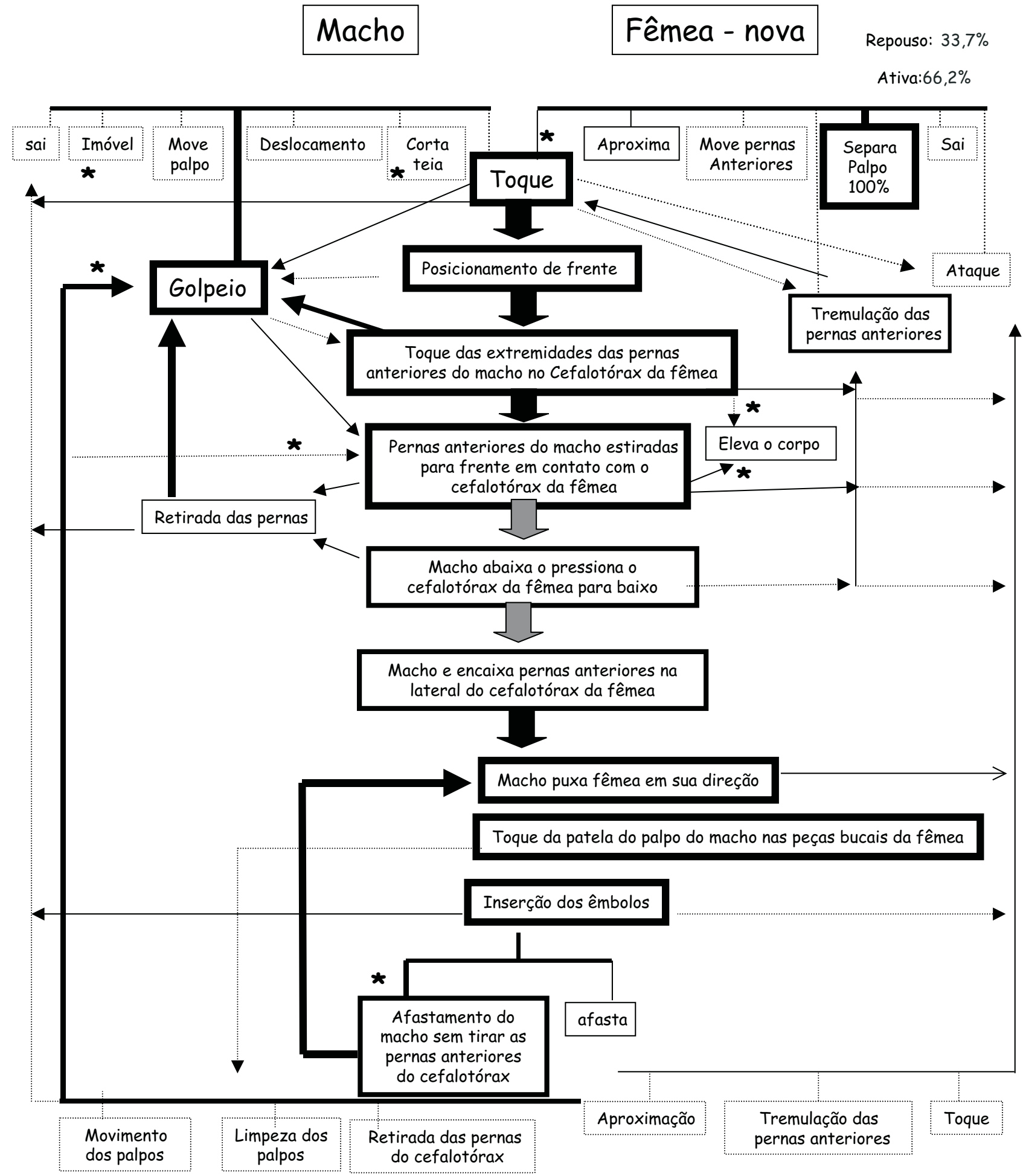

Figura 2. Fluxograma do comportamento sexual de fêmeas novas de L. laeta. ( $\cdots \cdots \cdots \cdots \cdot \ldots . . .0,1-25 \%-26-50 \%-51-75 \%-76-100 \%)$. Os valores significativamente diferentes $(p<0,01)$ acompanhados do asterisco.

Revista Brasileira de Zoologia 24 (4): 865-872, dezembro 2007 


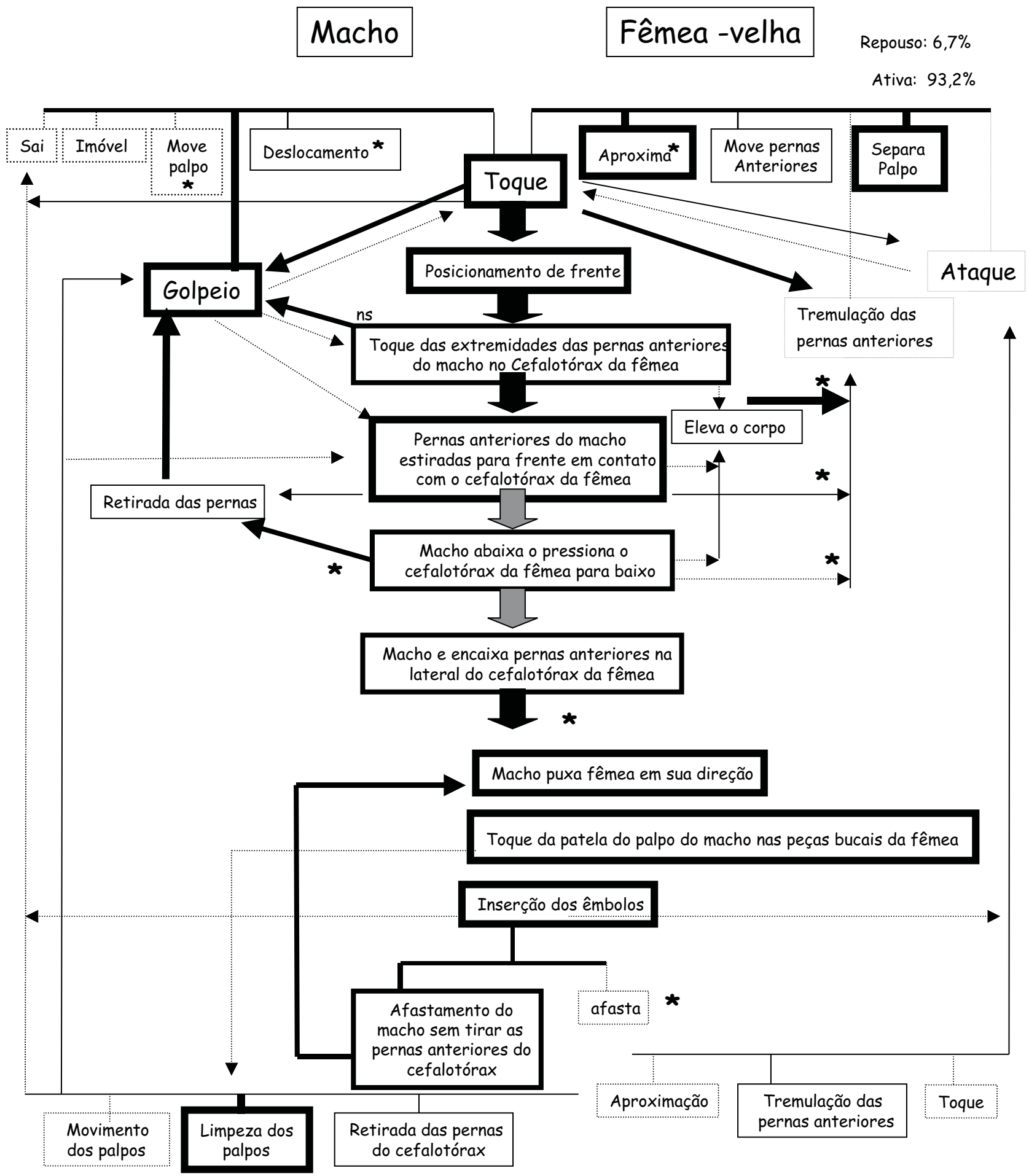

Figura 3. Fluxograma do comportamento sexual de fêmeas velhas de L. laeta. (…….. 0,1-25\%— 26-50\% — $-51-75 \%-76-100 \%)$. Os valores significativamente diferentes $(p<0,01)$ acompanhados do asterisco. 
Tabela I. Duração do reconhecimento (em segundos), tremulação, cortejo, cópula, pós-cópula e número médio de exibição do golpeio, tremulação e inserções em interações com e sem cópula em testes com fêmeas velhas e novas. Letras diferentes representam médias significativamente diferentes.

\begin{tabular}{|c|c|c|c|c|}
\hline \multirow{2}{*}{ Variáveis } & \multicolumn{2}{|c|}{ Fêmea nova } & \multicolumn{2}{|c|}{ Fêmea velha } \\
\hline & Sem cópula & Com cópula & Sem cópula & Com cópula \\
\hline Duração média do reconhecimento & $\begin{array}{l}0,1 \pm 1,2 \\
(n=118 ; \text { i.v. } 0-13) a\end{array}$ & $\begin{array}{l}5 \pm 27 \\
(\mathrm{n}=30 ; 1-145) a\end{array}$ & $\begin{array}{l}20,9 \pm 45 \\
(\mathrm{n}=29 ; \text { i.v. } 0-183) b\end{array}$ & $\begin{array}{l}8 \pm 26 \\
(n=30 ; \text { i.v. } 8-130) b\end{array}$ \\
\hline Número médio de Golpeio & $\begin{array}{l}0,7 \pm 3,1 \\
(\mathrm{n}=118 ; \text { i.v. } 0-18) \text { a }\end{array}$ & $\begin{array}{l}5 \pm 3,7 \\
(\mathrm{n}=30 ; \text { i.v. } 1-14) a\end{array}$ & $\begin{array}{l}6,8 \pm 8,1 \\
(n=29 ; \text { i.v. } 1-24) b\end{array}$ & $\begin{array}{l}5 \pm 4,9 \\
(n=30 ; \text { i.v. } 1-22) a\end{array}$ \\
\hline Número médio de tremulação & $\begin{array}{l}0,4 \pm 2,2 \\
(n=118 ; \text { i.v. } 0-20) a\end{array}$ & $\begin{array}{l}2 \pm 3,6 \\
(\mathrm{n}=30, \text { i.v. } 1-19) a\end{array}$ & $\begin{array}{l}6,2 \pm 9,4 \\
(\mathrm{n}=29 ; \text { i.v. } 0-38) b\end{array}$ & $\begin{array}{l}4 \pm 4,9 \\
(n=30 ; \text { i.v } 1-23) a\end{array}$ \\
\hline $\begin{array}{l}\text { Duração média da tremulação a } \\
\text { cada vez que foi exibida }\end{array}$ & - & $\begin{array}{l}43,7 \pm 1,9 \\
(n=110 ; \text { i.v. }=1-11) a\end{array}$ & - & $\begin{array}{l}4,8 \pm 3,5 \\
(n=276 ; \text { i.v. }=1-24) a\end{array}$ \\
\hline $\begin{array}{l}\text { Tempo da interação despendido } \\
\text { para tremulação }\end{array}$ & - & $\begin{array}{l}19,2 \pm 25,3 \\
(n=30 ; \text { i.v. }=3-114) a\end{array}$ & - & $\begin{array}{l}59,8 \pm 73,3 \\
(n=30 ; \text { i.v. }=2-323) b\end{array}$ \\
\hline Duração média do cortejo & & $\begin{array}{l}652 \pm 623,8 \\
(n=39 \text { i.v. } 1-2697) a\end{array}$ & & $\begin{array}{l}500 \pm 450 \\
(n=60 ; \text { i.v.1-1907) b }\end{array}$ \\
\hline Duração média da cópula & - & $\begin{array}{l}80 \pm 88,2 \\
(n=30 ; \text { i.v. } 10-420) a\end{array}$ & - & $\begin{array}{l}127 \pm 144 \\
(\mathrm{n}=30 ; \text { i.v. } 2-806) a\end{array}$ \\
\hline Número médio de inserções & - & $\begin{array}{l}4 \pm 3,7 \\
(\mathrm{n}=30 ; \text { i.v. } 1-16) a\end{array}$ & - & $\begin{array}{l}5 \pm 4,3 \\
(\mathrm{n}=30 ; \text { i.v. } 1-25) a\end{array}$ \\
\hline Duração média da pós-cópula & - & $\begin{array}{l}204 \pm 253,6 \\
(n=30 \text { i.v. } 10-904) a\end{array}$ & - & $\begin{array}{l}302 \pm 366 \\
(n=30 ; \text { i.v. } 10-1665) a\end{array}$ \\
\hline $\begin{array}{l}\text { Duração média de interações sem } \\
\text { cópula }\end{array}$ & $\begin{array}{l}191 \pm 488 \\
(\mathrm{n}=118 ; \text { i.v. }=1-2880) \mathrm{a}\end{array}$ & & $\begin{array}{l}903(938 \\
(n=29 ; 1-3496) b\end{array}$ & \\
\hline
\end{tabular}

do comportamento copulatório foi mais freqüente em fêmeas novas $\left(\chi_{(1)}^{2}=204 ; \mathrm{p}<0,01\right)$ (Figs 2 e 3 ). O tempo médio despendido na pós-cópula foi $253 \pm 316$ segundos $(\mathrm{n}=60$; i.v. = 1-1665) e não diferiu entre fêmea nova e velha (Tab. I).

\section{DISCUSSÃO}

O comportamento sexual de L. laeta apresentou muitas características que parecem estar relacionadas com padrões específicos da linha de radiação evolutiva bem como com seu hábito sedentário associado à grande resistência a fatores abióticos, longevidade e agressividade. Os padrões comportamentais diferenciais entre as espécies podem ser reflexos de diferentes hábitos e habitats como espécies mais generalistas (L. intermedia) ou especialistas (L. laeta) (Fischer \& VAsConcellos-Neto 2005), ocorrência em lugares mais frios (L. laeta) ou quentes (L. gaucho Gertsch, 1967) (MARQues-DA-SiLva \& Fischer 2005) e que se deslocam freqüentemente (L. intermedia) ou são mais sedentárias ( $L$. laeta, L. hirsuta Mello-Leitão, 1931, L. gaucho) (Fischer \& VAsConcellos-Neto 2005), mostrando mais semelhanças entre o grupo laeta e gaucho, principalmente quanto à utilização da teia. No entanto, as maiores diferenças verificadas em L. laeta, parecem se relacionar com sua maior agressividade.

Os padrões motores exibidos no reconhecimento e cortejo de L. laeta foram semelhantes com os das aranhas do grupo gaucho - L. gaucho (RinALDI \& STROPA 1998) no que diz respeito à intensa utilização da teia com golpeios e tremulação das pernas, enquanto que as espécies do grupo spadicea - L. hirsuta (FISCHER \& Marques-Da-Silva 2001, L. intermedia (Fischer \& VAsconcellosNeto 2000) e reclusa - Loxosceles reclusa Gertsh \& Mulaik, 1940 (Hite et al. 1966) são mais características pela pulsação abdominal e vibração dos pedipalpos, padrões motores envolvidos na produção de sons (Uetz \& STRATTON 1982), não sendo a ausência de teia limitante para realização da cópula.

A natureza agressiva de L. laeta ficou evidenciada na postura da pré-cópula, duração da cópula e forma de afastamento do macho. Na fase copulatória L. laeta é a única entre as espécies já estudadas, em que o macho toca no cefalotórax da fêmea com suas pernas anteriores estiradas frontalmente, parecendo usar o ato comportamental como informação da distância da fêmea, sendo a manutenção das pernas sobre o cefalotórax da fêmea o padrão motor que determina a acinesia (GALIANo 1967). Ao contrário, para indução da acinesia machos de L. reclusa, L. intermedia e L. hirsuta se posicionam mais próximos das fêmeas usando a vibração dos pedipalpos em contato com pedipalpos e peças bucais da fêmea (Hite et al. 1966, Fischer \& Vasconcellos-Neto 2000, Fischer \& Marques-da-Silva 2001). Corroborando com a interpretação de maior agressividade de $L$. laeta, a duração da cópula foi mais rápida do que L. gaucho - 168 segundos (RINALDI \& STROPA 1998), L. intermedia - 861 segundos (Fischer \& VAsconcellos-Neto 2000) e L. hirsuta - 2251 segundos (Fischer \& Marques-DA-Silva 2001) e finalizada abruptamente sugerindo a pequena duração da acinesia. 
A comparação do comportamento sexual entre L. laeta e L. intermedia pode ser um elemento a mais na compreensão do padrão de distribuição das espécies no município de Curitiba e no Estado do Paraná. O cortejo de L. laeta, mais demorado do que L. intermedia contrapondo com o menor período despendido nas inserções dos êmbolos (Fischer \& VASCONCELlos-Neto 2000) e intensa utilização das teias no cortejo caracterizam a maior agressividade e hábito especialista de L. laeta. Esses resultados subsidiam a hipótese levantada por Fischer \& VAsConcellosNeto $(2003,2005)$ de que a ampla distribuição de L. intermedia está relacionada com seu hábito mais generalista, com uma freqüente locomoção fora da área da teia, menor agressividade e menor dependência das teias para cópula. Antagonicamente, $L$. laeta é mais especialista, com menor freqüência de locomoção, maior agressividade e intensa defesa do território. Deve-se considerar, ainda, que a fêmea de L. intermedia (Fischer \& VASCONCELlos-Neto 2000) permanece em acinesia após a cópula, além do fato da pós-cópula ser caracterizada por uma separação lenta, em que o ataque da fêmea é raro, enquanto a cópula de $L$. laeta sempre é finalizada de modo abrupto. Outro dado interessante é que a fêmea de $L$. laeta raramente copula fora da sua teia, enquanto a de $L$. intermedia copula nas duas situações (FISCHER \& VASCONCELlos-Neto 2000), reforçando a importância da teia densa para o comportamento sexual de L. laeta como substrato de comunicação e supressão da predação da fêmea.

A baixa freqüência de cópula em pareamentos que envolveram fêmeas novas parece ser devido a uma maior agressividade resultando em pouca receptividade, ao contrário das fêmeas velhas. Segundo Krafft (1982), a participação ativa da fêmea é de grande importância para realização da cópula, pois juntamente com outros sinais como presença de feromônios e produção de sons, compõem o repertório de identificação da espécie e da sinalização da receptividade para a cópula. No entanto, a sinalização da fêmea pode variar com a experiência (Foelıx 1996) e idade, além de estímulos como sede e fadiga poderem modificar a resposta do macho aos sinais da fêmea (Krafft 1982). Para $L$. laeta além das fêmeas velhas serem mais receptivas do que as novas, também exibiram maior número de padrões motores; a grande longevidade (mais de nove anos) associada à alta resistência a inanição (LowRIE 1980), podem ser fatores que favoreçam que a fêmea permaneça receptiva por um maior período de tempo. No entanto, esses dados são confrontantes com GaLIANO $\&$ HaLl (1973), pois segundo os autores, conforme transcorre o tempo após a última ecdise a fêmea fica menos atrativa e também menos receptiva. Outro ponto observado no presente estudo foi a maior atividade e agressividade das fêmeas mais novas corroborando com registros de Galiano \& Hall (1973), o que pode estar relacionado à menor quantidade de teias. Para aranhas errantes como Lycosa tarentura fascüventris (Linnaeus, 1758) (Lycosidae) Fernández-Montraveta \& Ortega (1990) verificaram justamente o contrário de L. laeta, fêmeas jovens mais receptivas e cortejo mais demorado. Essa variação pode ser devido à grande longevidade de L. laeta e a adoção de hábitos mais se- dentários, os quais promovem maior deposição de fios de seda em uma mesma área, favorecendo a cópula com fêmeas velhas.

Os dados obtidos com o presente estudo se constituem de um importante subsidio para compreensão dos fatores que determinam a atual distribuição do gênero Loxosceles em Curitiba, com a maior distribuição e prevalência de L. intermedia. A análise do comportamento sexual de L. laeta vem somar às evidências levantadas de um perfil mais sedentário, territorial e agressivo quando comparada com L. intermedia. O comportamento diferencial em fêmeas novas e velhas corrobora a hipótese de que a maior atividade e agressividade das fêmeas novas estão relacionadas principalmente com a quantidade de teias, resultando em maior receptividade na fêmea velha, o que vem a ser uma estratégia importante para um animal sedentário.

\section{AGRADECIMENTOS}

Emanuel M. da Silva, e equipe, do Centro de Produção e Pesquisa de Imunobiológicos (CPPI).

\section{REFERÊNCIAS BIBLIOGRÁFICAS}

Andrade, R. M.G.; W.R Lourenço \& D.V. Tambourgi. 2000. Comparison of the fertility between Loxosceles intermedia and Loxosceles laeta spiders (Araneae Sicariidae). Journal of Arachnology 28: 245-247

Buckup, E.H. 1980. Variação interpopulacional dos receptáculos seminais em aranhas do grupo Spadicea do gênero Loxosceles Heinecken \& Lowe, 1832 (Araneae; Scytodidae). Iheringia, Série Zoologia, 55: 137-147.

Fernández-montraveta, C. \& J. ortega. 1990. Some aspects of the reproductive behavior of Lycosa tarentula fasciiventris (Araneae; Lycosidae). Journal of Arachnology 18: 257-262.

FIsCHER, M.L. 1994. Levantamento das espécies do gênero Loxosceles Heinecken \& Lowe, 1832 no município de Curitiba, Paraná, Brasil. Estudos de Biologia 38: 63-88.

Fischer, M.L.\& E.M. Marques-DA-Silva. 2001. Comportamento sexual de Loxosceles hirsuta Mello-Leitão, 1931 (Araneae; Sicariidae) Estudos de Biologia 47: 7-14.

Fischer, M.L.\& J. VAsConcellos-Neto. 2000. Comportamento sexual de Loxosceles intermedia Mello-Leitão, 1934 (Aranae; Sicariidae). Revista de Etologia 2: 31-42.

Fischer, M.L.\& J. Vasconcellos-Neto. 2003. Determination of the maximum and minimum lethaltemperatures(LT 50) for Loxosceles intermedia Mello-Leitão,1934 and L. laeta (Nicolet, 1849) (Araneae, Sicariidae. Journal of Thermal Biology 28 : 563-570

Fischer, M.L. \& J. Vasconcellos-Neto. 2005. Microhabitats Occupied by Loxosceles intermedia and Loxosceles laeta (Araneae: Sicariidae) in Curitiba, Paraná, Brazil. Journal of Medical Entomology 42 (5): 756-765.

Foelix, R.F. 1996. Biology of Spiders. Cambridge, Harvard University Press, $2^{\text {nd }}$ ed., 330p.

Galiano, M. E. 1967. Ciclo biologico e desarollo de Loxosceles

Revista Brasileira de Zoologia 24 (4): 865-872, dezembro 2007 
Laeta (Nicolet, 1849). Acta Zoologica Lilloana 23: 431-464.

Galiano, M.E \& M. Hall. 1973. Datos adicionales sobre el ciclo vital de Loxosceles laeta (Nicolet, 1849) (Araneae) Physis 32: 277-288.

GerTsch, W. 1967. The spider genus Loxosceles in South America. Bulletin American Museum Natural History 136: 121-182.

Hite, M.J.; W.J. Gladney; J.L.J.R. Lancaster \& W.H. Whitcomb. 1966. Biology of brown recluse spider. Agricultural Experimental Station Bulletin 711: 2-26.

KRAFFt, B. 1982. The significance and complexity of communication in spiders, p. 15-66. In: P.N. WitT \& J.S. RovNer (Eds). Spider communication: mechanisms and ecological significance. Princeton, Princeton University Press, 441p.

Levi, H.W. \& A. Sirelman. 1964. The biology and control of the South American Brown spider, Loxosceles laeta (Nicolet), in a North American focus. America Tropical Medicine Hygiene 13: $132-136$.

LowRIE, D.C. 1980. Starvation longevity of Loxosceles laeta (Nicolet) (Araneae). Entomology News 91: 130-132.

Lowrie, D.C. 1987. Effects of diet on the development of
Loxosceles laeta (Nicolet) (Araneae, Loxoscelidae). Journal of Arachnology 15: 303-308.

Marques-Da-Silva, E. \& M.L. Fischer. 2005. Distribuição das espécies do gênero Loxosceles Heinecken \& Lowe, 1835 (Araneae; Sicariidae) no Estado do Paraná. Revista da Sociedade Brasileira de Medicina Tropical 38: 331-335.

RinALDI, I.M.P. \& A.A. STROPA. 1998. Sexual behaviour in Loxosceles gaucho Gertsch 1967 (Araneae; Sicariidae). Bulletin of the British Arachnological Society 11: 57-61.

Sezerino, U.M.; M. Zannin; L.K. Coelho; J. Gonçalves Jr; M. Grando; S.G. Mattosinho; J.L.C. Cardoso; V.R.D. Eickstedt; F.O.S., FranÇA; K.C. Barbaro \& H.W. FAn 1998. A clinical and epidemiological study of Loxosceles spider envenoming in Santa Catarina, Brazil. Transactions of the Royal Society of Tropical Medicine and Hygiene 92: 546-548.

Uetz, G.W. \& G.E. Stratton. 1982. Acoustic communication and reproduction isolation in spiders, p. 123-159. In: P.N. WITT \& J. S. ROVNER (Eds). Spider communication: mechanisms and ecological significance. Princeton, Princeton University Press, 441p.

Recebido em 18.VI.2007; aceito em 12.XI.2007. 